\title{
Design Science in Practice: Design and Evaluation of an Art Based Information System to improve Indoor Air Quality at Schools
}

\author{
Blinded for Review
}

\begin{abstract}
Indoor air quality has a significant effect on human performance. In addition, many health issues can be traced back to bad indoor room-climate. However, especially in Europe, pupils spend a majority of their learning life in school classes affected by poor room climate. Without an automatic heating, ventilation and air conditioning system these pupils and their teachers have to rely on manual ventilation by opening windows. Thereby, they often lack fundamental room climate quality information to effectively guide their behavior. Information systems (IS) and sensor technology can be a remedy to these challenges. Existing room climate monitoring systems regularly reveal major shortcomings, e.g. in respect to user interfaces, presentation of data, and systematic engagement. We want to address the aforementioned shortcomings and present an art IS, which reflects room conditions in real time through modifications of depicted art. The artifact is evaluated in a field experiment, conducted in an Austrian grammar school. The evaluation reveals that room climate measured in $\mathrm{CO}_{2}$ can indeed be improved significantly. In addition, pupils also perceive a significant room climate improvement. By implementing and evaluating the presented IS we pursue a research avenue which is dedicated to a more fundamental research questions: "Are hedonic, art-based IS superior to utilitarian, non-art-based IS in respect to usage and impact?"
\end{abstract}

Keywords: Human-computer interaction, ambient displays, art information systems, pervasive computing

\section{Introduction}

The negative effect of poor indoor climate conditions on occupants is a wellresearched phenomenon. In 1983 the World Health Organization defined this phenomenon as the sick building syndrome (SBS). SBS refers to symptoms such as skin reactions, non-specific hypersensitivity, mental fatigue, headache, nausea, and dizziness among people staying in respective buildings [1] [2]. Those negative effects have been regularly detected in office buildings [3] or schools [4]-[8]. Research primarily conducted in school environments show that, apart from effects on health, room climate additionally influences concentration and attendance [8]. More specifically, negative effects on simple calculations, word processing [3] as well as general math results [7] have been demonstrated. 
One of the key root sources for SBS is ventilation. Heating, ventilation and air conditioning systems (HVAC) ideally guarantee good room climate. However they are often poorly installed, setup and operated. Moreover, older professional buildings and residential homes, especially in Europe, are rarely equipped with an automatic ventilation system. Proper manual ventilation is therefore crucial to improve indoor air quality. This also holds true for the majority of European schools, where fresh air is usually provided by opening windows.

Sensing room climate can be very hard for humans as the human body is unable to sense important room climate parameters. Although we have a good sense for temperature, carbon dioxide levels, for example, cannot be sensed directly at all. This problem is known and room climate sensors are used in office buildings as well as in residential buildings to control the settings of HVACs or the users' own ventilation behavior. Monitoring Systems, like the commercial products Netatmo even allow detailed data analysis provided through a smartphone application. Furthermore, those applications provide user guidance, for example calculating an aggregated room climate index generated on the basis of temperature, carbon dioxide, humidity and noise, and having a traffic light indicating how good the overall room climate is. However, engaging people in tracking their room climate on a regular basis is far from being easy. While starting up a smartphone app on a regular basis is cumbersome, reading the values on a standard gauge is not very appealing. Furthermore, providing enough help to interpret room climate data is challenging. This is noteworthy, as people still have difficulties in understanding scientific notations such as carbon dioxide level expressed in ppm (parts per million).

In this paper we present and evaluate an IS to promote pupils ventilation behavior in classrooms via a visual feedback system - the " $\mathrm{CO}_{2}$-Albert". We developed $\mathrm{CO}_{2}$ Albert enabling pupils to overcome a lack of information availability and -processing that makes it hard or even impossible for them to direct their behavior (ventilation to improve $\mathrm{CO}_{2}$ conditions) within a given feedback system. $\mathrm{CO}_{2}$-Albert is a feedback system being equipped with standard room climate sensors for temperature, humidity, and carbon dioxide. In contrast to conventional monitoring systems a display embedded in a standard art frame presents the current room climate on the basis of a picture of Albert Einstein. Changing room conditions are reflected in modifications of the picture in real-time. While the focus of this paper is on $\mathrm{CO}_{2}$ and ventilation we want to transfer the design of this art monitoring system to other cases like diabetes, i.e. we want to visualize $\mathrm{HbA1c}$ and Hypoglycemia in a $\mathrm{CO}_{2}$-Albert-like feedback system.

The paper is structured as followed: Having outlined the motivation, section two depicts the existing knowledge base. Section three presents our research methodology. Section four outlines the design process. By demonstrating the artifact in a field test we evaluate its performance (section five). Finally, in section six we conclude our findings and present implications as well as limitations. 


\section{Knowledge Base}

\subsection{Fostering health behavior on the basis of IS-enabled feedback}

The rise of IS in the 90's also found its way to health care as IS proved to be costefficient and quality increasing [2-4]. The possibilities in processing information were soon used to give patients individualized feedback in order to support them improving their health behavior. This computer-tailored feedback was found to be effective in dietary [5], smoking [6], cancer [7] and health risk appraisal [8]. For an overview see [9].

In general, four stages of feedback IS can be distinguished. First-stage approaches provide general information about health issues. With email emerging as a vivid communication tool, attempts were made to use this channel for low cost and high reach information provisioning [10]. Second-stage approaches provide behaviordirected information personalized for a specific patient. There is broad evidence, that such second-stage information provisioning has a significant impact on physical activity, dietary behavior and alcohol consumption [11]. Third-stage approaches use multiple feedback loops in order to repeatedly readjust behavior [12]. This strategy proved powerful to increase physical activity [13], dietary [5], weight $[14,15]$ and diabetes self-management. For an overview see [16]. Latest research focuses on a fourth stage of feedback that comes constantly and in real-time. A very prominent example is biofeedback [17], [18]. The work presented in this paper can be attributed to the latter fourth stage type of feedback IS.

Research provides evidence that higher-level feedback approaches building upon more interactive interventions have a higher impact than lower level approaches. Brug et al. found that people ate more fruit and vegetables given second-stage feedback compared to the simple provision of general information [5]. This effect could even be enhanced with iterative feedback. Similar results were obtained in weight reduction [15] and risk behavior [8].

\subsection{Feedback as a means to drive and direct behavior}

There are several theories explaining the causes for behavior change in the field of health [9]. In the context of feedback IS, Control Theory [19] provides a powerful lens to understand the impact of these systems. Control Theory uses the basic cybernetic concept [20] of the negative feedback loop (NFL). A NFL starts with comparing an input capturing information on the present state to a desired reference value, the target state. Any discrepancy leads to behavior decreasing that discrepancy. The new present state then initiates a next NFL.

The origin of the reference value may stem from superordinate goals, such as beliefs ("fresh air will make me be able to concentrate better"), norms ("one should always breathe fresh air") or desires ("I would like better room climate") [19],[21]. Superordinate goals can influence subordinate goals in a hierarchical feedback system, e.g. "I love good room climate and therefore room temperature has to be $20^{\circ} \mathrm{C}$." The means to achieve a superordinate goal via its subordinate goals is a script. A 
script is defined as a "general course of action, that incorporates a series of implicit ifthen decisions" [19], e.g. "if room temperature is above $20^{\circ} \mathrm{C}$, I have to open the window."

In order to make a feedback loop drive someone's behavior towards a certain goal, three requirements have to be fulfilled. First, the information of the present state has to be available. Second, the goal has to be appealing. And third, the individual needs to know what action to take to decrease present-target discrepancy, i.e. one has to have an effective script. The latter is an issue of knowledge and may therefore be solved with education. When it comes to health behavior present information is often far from perfect [22]. Moreover, the goal to be achieved may be discounted due to temporal distance, may get out of focus due to distraction, or may simply lack of importance [23]. The key to keep someone "on track" therefore lies in the format of the presentation to facilitate information processing and to increase awareness and goal attractiveness.

\subsection{The role of information visualization, storytelling and awareness in feedback}

Information visualization is a process that transforms data into a form that the human visual system can perceive the embedded information [24]. Its goal is to foster the observation and the understanding of data. Therefore information is made easier to process and thus more appealing [25]. There are no limits of how feedback is visualized. This offers the possibility of letting users work on a cover-feedback system that is more attractive than the original one [26]. In a first technical test setup, pupils behavior seemed to focus on restoring the natural state of the displayed modified portrait. Vital feedback and lively discussions were focused on how to make the displayed person ("cover"-feedback system) look "normal". Hardly any feedback was directly related to improving room climate (original feedback system). The pupils' actions were driven by a need for balance and order for the displayed manipulated picture of Albert Einstein [27-29].

A key research area for information visualization involves creating visual metaphors. Metaphors to represent and support the tasks of understanding of the visualized information [26]. Raw data and information are often complex, high-volume and time-dependent. Therefore, visual metaphors can foster compliance, motivation and help direct behavior. One key concept of information visualization in feedback systems is storytelling [26]. Storytelling is a universally present feature of human communication. Furthermore, it is a proven way to convey great quantities of information in a compelling, effective and efficient way [26], [30]. Technology now provides us with the means to convey information in a story-like fashion thereby leveraging the advantage of traditional storytelling. The paper at hand, for example, builds upon art visually telling a story about a suffering genius (Albert Einstein getting pale green).

Providing information is not enough for an internal feedback loop to drive behavior. Carver and Scheier propose that engagement in a loop "partially depends on the person's focus of attention" [19] (p. 120). While attention makes sensory inputs available for action, memory or thought, awareness is based on attention and implies that 
there is neural activity that produces conscious experience [31]. Shifting attention to the salient standard, i.e. increasing awareness, leads to "a tendency to compare one's perceptions of one's present state or behavior against the standard, leading (when possible) to a reduction of perceptible discrepancies between the two" (p.120). Awareness should further lead to "increased conformity to salient behavioral standards" (p.121). This holds for several behaviors like aggression [32-34] or resource allocation [35]. In the context of visual feedback discrete alerts in the form of caution or warning lights are commonly used as proven means to raise awareness [24]. In our case the attention-raising modified Albert should therefore motivate pupils to take action regulating room climate.

\section{$3 \quad$ Research Methodology}

The objective for this research is to develop, implement and evaluate an artifact that is novel and innovative. Therefore the proposed methodology is Design Science Research (DSR) [36]. We follow the DSR process suggested by Peffers et al. [37] outlined in Figure 1.

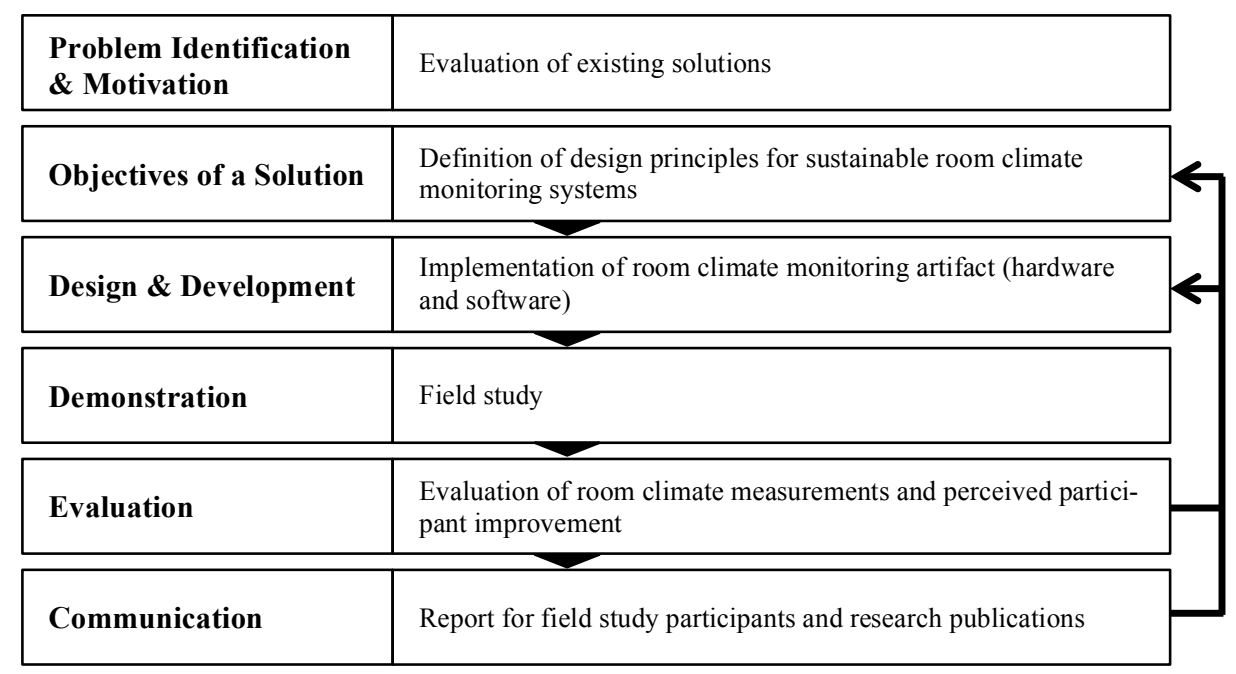

Fig. 1. Research methodology based on [37]

The first three steps of the process are "problem identification \& motivation", "objectives of a solution" and "design \& development". These phases have been outlined extensively in previously research [38]. Thus, section 4 of this paper will outline essential findings of these three steps. The fourth step is the demonstration of the artifact. We demonstrate our artifact in a field setup by installing 10 artifacts in a grammar school. The evaluation of the artifact (step five) is presented in section five. 


\section{Design and Development}

\subsection{Evaluation of existing solutions}

As part of the DSR process we have tested multiple solutions that are currently available to monitor indoor room climate. Systems are available from standard gauges [39] to more sophisticated internet-enabled sensors [40]. We identified the following key problems [38]:

- Complex, non-intuitive user interfaces: Displaying blunt data on a gauge or a digital display requires a lot of prior user knowledge to be effective. Data has to be interpreted and compared against known target values. While an average user can perform interpretation of temperature, e.g. interpreting $\mathrm{CO}_{2}$ values in parts per million (ppm) can indeed be very challenging.

- Lack of systematic engagement: Room climate is specific for each individual room and has to be measured continuously when the user is present. Furthermore, the room climate IS should specifically engage the user in case of poor room climate conditions. Standard room climate systems tend to keep the level of engagement constant, thereby losing the users intention already during periods of good room climate.

- Long-term usage challenges: As discussed, current systems lack self-explanatory user interfaces and do not engage the user when the room climate conditions worsen. This ultimately challenges their long-term usage and impact. However, there is a new generation of internet-enabled system using smart phone apps or other mobile front-end devices to display information. While these systems overcome some of the discussed challenges they bring their own set of issues. Starting up an app is cumbersome compared to an always-visible measurement device. Push notifications can be used as a remedy to inform the user even if she does not start the app. However, these notifications are often perceived as intrusive and disturbing, especially when the user is not in the corresponding room currently experiencing bad conditions.

\subsection{Design principles}

Building upon prior research we derived the following four design principles (DP) for the development of a sustainable room climate monitoring system [38]:

- [DP1] Draw attention only when necessary: We want to build a monitoring device that is unobtrusive and remains so unless attention is really necessary. Without the need of the users attention the device displays art in its natural form integrate seamlessly into the surroundings [41]. With decreasing room climate conditions the continuous modifications enables the attentive user to react. When attention is necessary the modification to the art is in full forming, drawing attention of the whole surrounding. 
- [DP2] Connect to people emotionally: We want to go beyond designing a system that builds upon rationality and cognitive thinking, i.e. leverage emotions and psychological incentives [29]. By creating a visual metaphor through the modification to the art the user easily perceives the connection between room climate and humans health.

- [DP3] Provide choice: The design of the artifact is supposed to foster usage and post acceptance. Therefore, we want to leverage the advantages of personalization [42] and allow the user to customize the solution to a specific taste [43].

- [DP4] Learn from the past: Apart from having the current room climate displayed on the spot with the display, the analysis of historic room climate data is possible via a platform. Thereby, users can adjust the settings of their heating and ventilation system or conduct construction measures to improve indoor roomclimate.

\subsection{Design and features of the artifact}

The goal of this research is to build a room-climate monitoring system that fosters sustainable ventilation behavior by integrating an innovative user interface, as well as descriptive and injunctive feedback [13]. We do so by implementing a hedonic userinterface by incorporating art. Therefore we build a standard wooden art frame that is equipped with standard room climate sensors, and internet-capable minicomputer and a LCD display to illustrate art. In contrary to a standard framed picture, the displayed art gets modified in real time according to the continuously measured room climate.

Our first prototype showed Marilyn Monroe (Albert Einstein was introduced later) and manipulated. As pointed out by [43] the idea behind using a face is that it is easily recognized, including changes in the appearance following DP2. In general, low temperature is presented by coloring the lips of the portrayed person blue. Likewise high temperatures, exceeding a predefined threshold, transform the lips neon yellow. The intensity of the lips color reflects the extent that the threshold is being exceed/fallen below. Humidity levels are presented by modifications to the skin. Values below a threshold are depicted as a dry skin with cracks. Exceeding the optimal humidity value forms sweat like droplets on the skin. Likewise, the indoor carbon dioxide level is also presented by a modification to the skin. The level of exceedance of each measurement is presented by the intensity of the modification. Figure 2 shows all the modifications in full intensity.
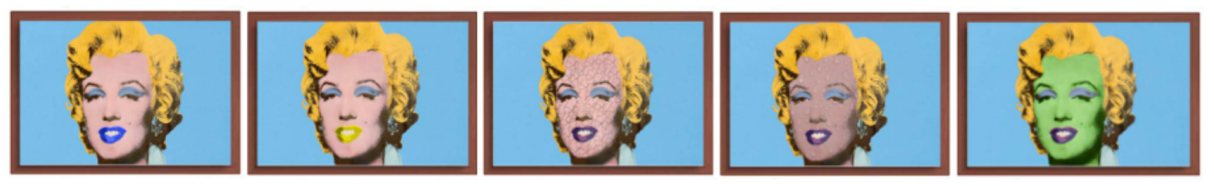

Fig. 2. Modifications according to room-climate conditions (from left: 1. Low temperature, high temperature, low humidity, high humidity, high carbon dioxide level) 
This section will further outline the hardware used for the implementation of the design. A wooden art frame was equipped with standard room climate sensors, an internet-capable minicomputer and a LCD display to illustrate art. The artifacts display is a 23-inch TFT-LCD panel. Having a brightness of $250 \mathrm{~cd} / \mathrm{m}^{2}$ and viewing angles of $89^{\circ}$ in each direction the displays are not recognized as displays but as a normal print of art. The wooden frame hides the metallic edges of the panel and provides enough space in the back of the display to house the sensors, the computer and electrical power supply. The Raspberry Pi [44], a Linux based small computer, in the back of the display was used to interact with the sensor and display the art using the built in graphic chip. The Raspberry Pi provides 16 GPIO (general purpose input output) and SPI, I2C as well as an AURT interface to connect sensors. Sensing room climate levels we used the K33 OEM [45] module from Sense Air measuring carbon dioxide concentration with a no dispersive infrared sensor. Communicating with the Raspberry $\mathrm{Pi}$ the sensor provides a UART interface. Figure 3 shows the artifacts inner life with the mentioned hardware.

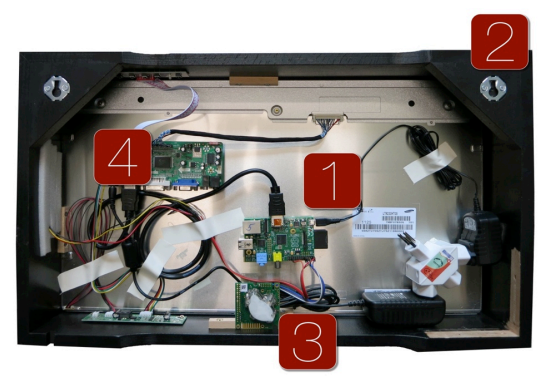

Fig. 3. Image showing the back of the prototype; Legend: Raspberry Pi [1], Wooden Frame [2], K33 OEM [3], LCD Display + Display Controllers [4]

Beside the display we provide a web portal to change settings. This way the display itself stays a true plug and play product without a complicated user interface. In the portal users can change the displayed art as well as adapt the behavior of the art. A comprehensive system-architecture enables the described functionalities. A SQL database (PostgreSQL) [46] stores historical data, handles user administration and provides threshold data. A second database stores all the art content that is available for download. All front-end devices communicate with the backend over a middleware written in NodeJS [47].

\section{Demonstration and Evaluation}

To evaluate the artifact, we conducted a field study in an Austrian Grammar School. The goal of this test is to improve the indoor air quality. We want to show that our system improves indoor air quality (IAQ). As shown in various previous research activities carbon dioxide levels are a good indicator for IAQ [48-50]. Hence we hypothesize: 
Hypothesis 1 (H1): Classrooms with an artifact have a better IAQ in respect to carbon dioxide than classrooms without an artifact.

Unlike other countries, Austria, the location of the field test, has no binding $\mathrm{CO}_{2}$ regulations for schools. However local authorities issued three official $\mathrm{CO}_{2}$ recommendations. The targeted carbon dioxide concentration for mechanically ventilated classrooms (de facto standard in Austria) is below 800 parts per million (ppm). The average over a single lesson shall not exceed 1'000 ppm. Single measurements during lessons should not be above 1'400 ppm.

By focusing the artifacts design on the depicted design principles we further hypothesize, that the students like and use the system, hence ultimately "feel" the improved air quality. We thus hypothesize:

Hypothesis 2a (H2a): The perceived improvement of well-being is higher in classes with the artifact.

Hypothesis $2 b$ (H2b): Students' level of engagement in improving indoor air quality is higher in classes with the artifact.

\subsection{Pre-test}

Before the start of the field-test we pre-tested the first version of the artifact. We installed Marilyn Monroe in a single classroom to test robustness of the system and general system acceptance. The pre-test lasted for 22 days (550 hours), including 65 hours of occupancy during classes.

The recorded data revealed $\mathrm{CO}_{2}$ levels that, even with our feedback system, in $18 \%$ of the time $\mathrm{CO}_{2}$ concentration exceed $1000 \mathrm{ppm}$. Additionally in $5 \%$ of the recorded time the concentration exceed concentration levels of $1500 \mathrm{ppm}$. Figure 4 shows the time series of a typical school day with occupancy of pupils during classes (depicted in green).

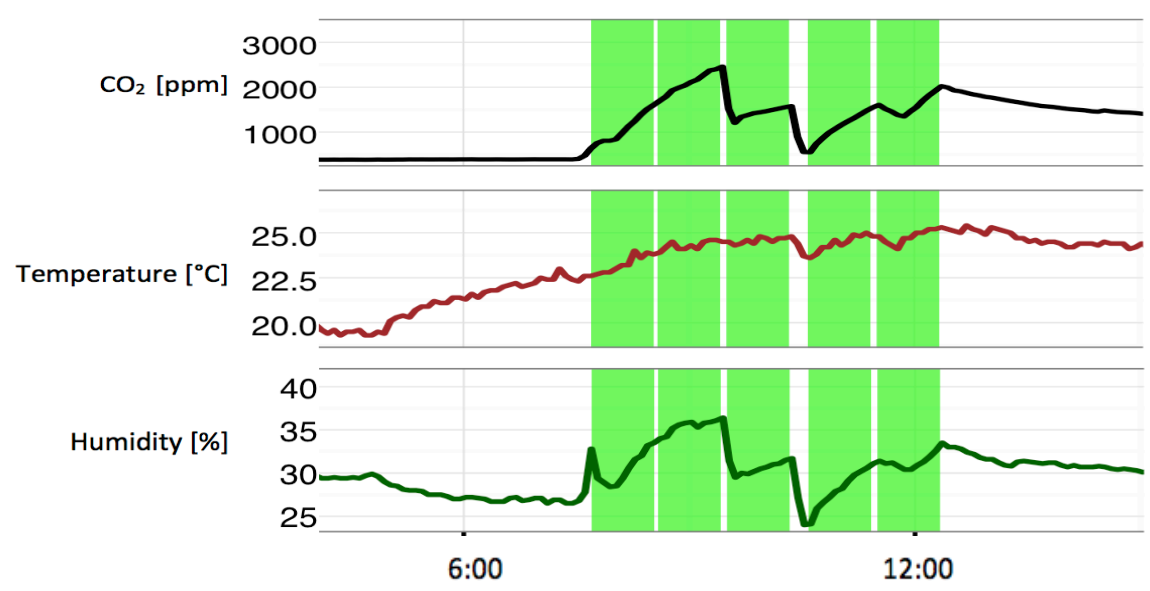

Fig. 4. Time series of room climate level during typical school day. 
A look at the time series in Figure 4 reveals that, especially for the cold winter season, humidity and carbon dioxide levels show similar behavior. This is due to the fact that in buildings without humidifiers the exhaled air is the only source of humidity (increase of humidity goes along with increase of $\mathrm{CO}_{2}$ ). Opening a window for fresh air leads to decreasing $\mathrm{CO}_{2}$ concentrations as well as decreasing humidity (in winter outside air is very dry).

After receiving first feedback form students as well as teachers, we adapted the IS in accordance with the introduced DPs. First, after a discussion with students and on the basis of DP2 we chose a portrait photograph of Albert Einstein for the context of a grammar school. We then adapted the changes of the appearance of Albert Einstein according to the proposed regulations as shown in Figure 5.
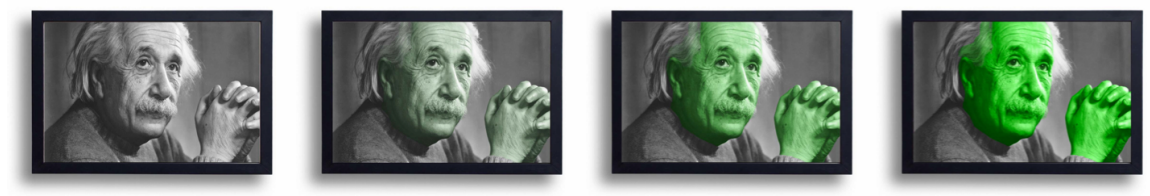

Fig. 5. Albert in corresponding $\mathrm{CO}_{2}$-concentrations; from left: $<800,1000,1400,>1500$ ppm

Second, we removed monitoring temperature and humidity and the corresponding modifications to the art. This is done following DP1. It is not the purpose of the monitoring system to draw attention to conditions when the ability to react is not available. Having no control over the heating system and not having a humidifier in classrooms, pupils cannot react to these conditions in the setting at hand. According to the theory of self-efficacy [51] we assume that students' motivation to engage with the system would decrease showing temperature and humidity without appropriate means to react.

\subsection{Field test}

For the field test we equipped 10 classrooms with the artifact. To test our hypotheses regarding the improvement of IQA we used A/B testing. Group A, the experimental group, had artifacts that changed Albert Einstein's appearance, as previously described, by measuring the $\mathrm{CO}_{2}$ concentration every four seconds and modifying Albert's skin. Group B, the control group, was also equipped with artifacts. However, the devices in the control group did not react on room climate. The device of the control group thus only displayed Albert Einstein in its unmodified form. In both groups the $\mathrm{CO}_{2}$ concentration was saved to our backend every 5 minutes for analysis and evaluation. Each of the 10 classes was randomly assigned to the experiment group or control group. All 10 classes were given an introduction to the importance of room climate and their ability to change it. The 5 classes of the experimental group were also introduced to the functionality of the device. Figure 6 shows the installation of the artifact. The field test was conducted over a period of 8 weeks. In that period 519 school lessons where held all together: 255 in the experimental group and 264 in the control group. 


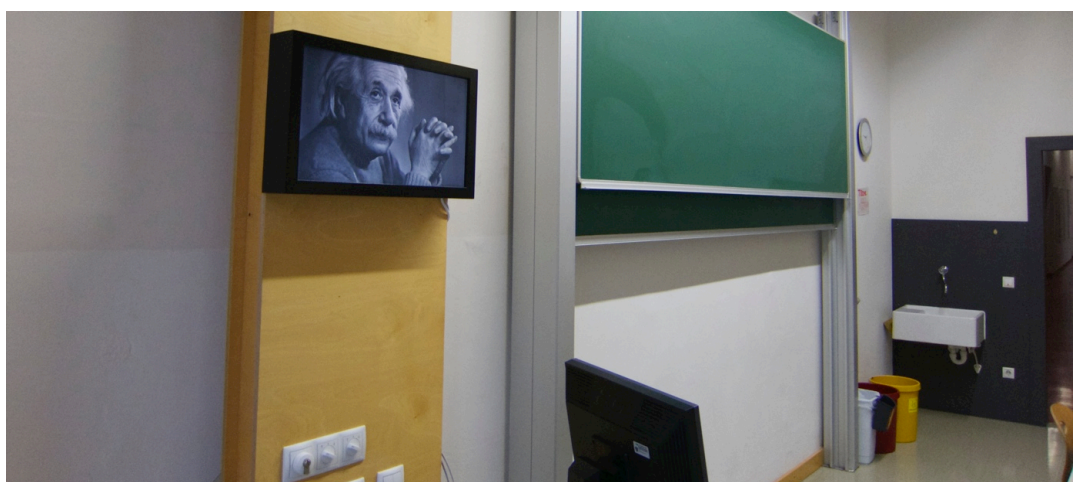

Fig. 6. Photograph of the installed prototype in a classroom of a secondary school in Austria

We applied multiple regression analysis to examine the impact of the artifact on the improvement in IAQ during the experiment. This method was chosen for three reasons. First, the field test's overall goal was to prove that the system works and has a positive impact on room climate. Hence the average carbon dioxide (dependent variable) should be lower in school classes with an artifact than in the control group classes. Second, multiple regression analysis allows us to reflect potential confounds, i.e. outside temperature and numbers of students. And third, because it also allows us to incorporate the individual classrooms in the analysis. Thereby, we can rule out effects that root in the characteristics of the classroom.

The latter two reasons require further explanation. The field test was done in the last two months of the school year, May and June. In May and June the outside temperature varies strongly both over different days, and also within the course of a day. After cold mornings (minimal temperature during the period: $6^{\circ} \mathrm{C}$ ) the temperature rises quickly from lesson to lesson (maximum measured temperature $28^{\circ} \mathrm{C}$ ). Therefore opening a window in the cold mornings is correlated with a discomfort due to the cold and solely done to provide fresh air. At higher temperatures, the windows can remain open providing constant fresh air, erasing the artifacts impact on IAQ. The number of students was taken into the model because for certain lessons, the classes are divided, resulting in a smaller number of students and smaller decrease in IAQ during lessons. The individual rooms were modeled into the analysis because of the different physical characteristics (size, exposition, number of windows).

The results of the analysis, shown in table 1, support our first hypotheses (H1). There is a significant positive relationship between the artifact and measured $\mathrm{CO}_{2}$. In addition, the outside temperature has a positive impact on $\mathrm{CO}_{2}$. Finally, number of students is negative related to $\mathrm{CO}_{2}$. 
Table 1. Results of multiple regression analysis

\begin{tabular}{lrrrr}
\hline & Coef. & Std. Err & t & P > t \\
\hline Artifact & -149.59 & 70.03 & -2.14 & 0.016 \\
Outside Temperature & -23.96 & 2.95 & -8.12 & 0.000 \\
Number of Students & 4.85 & 2.28 & 2.12 & 0.017 \\
\hline
\end{tabular}

To test the robustness of the key findings of the field test and to further examine $\mathrm{H} 2 \mathrm{a}$ and $\mathrm{H} 2 \mathrm{~b}$ we collected qualitative feedback via a questionnaire at the end of the 8 weeks field study. We obtained the data of 181 students ( 97 female, 84 male) from the age of 14 to $17\left(\mathrm{M}_{\mathrm{age}}=15.1, \mathrm{SD}=1.2\right)$. Via a 7-point Likert scale, ranging from 1 (absolutely not) to 7 (absolutely) we measured the level of agreement to statements concerning students' perceived improvement of IAQ. Furthermore, students' perceived engagement to improve room climate was collected.

To examine H2a, i.e. perceived level of improvement, students had to evaluate 4 easy statements like: "Indoor air quality has improved since Albert was installed in the classroom" or "Since Albert was installed in our classroom, I feel more comfortable in our classroom". A t-test, shown in Figure 7, revealed that students in classes with the artifact had a significantly higher perceived improvement of well-being, $\mathrm{t}(180)=-9.17, \mathrm{p}<0.001$.

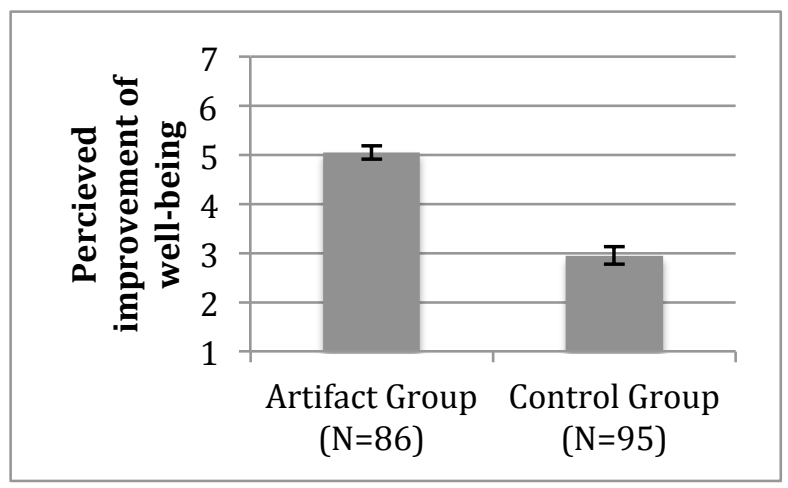

Fig. 7. Mean perceived improvement of well-being by group members

With H2b we wanted to test students' perceived engagement to improve room climate, an indicator on the usage of the system. Students were asked for their level of agreement to statements such as: "Since Albert was mounted in our classroom, I take care that our classroom is well ventilated" or "Also in the future, I will take care that our classroom is well ventilated". A second t-test depicted in figure 8, revealed that the students perceived level of engagement is also significantly higher in classes with an installed and functioning artifact, $\mathrm{t}(179)=-5.26, \mathrm{p}<0.001$. 


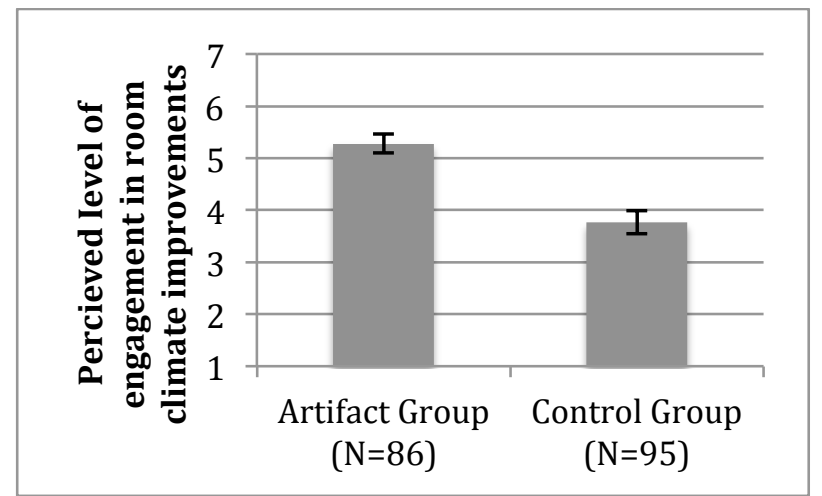

Fig. 8. Mean perceived level of engagement in room climate improvement by group members

Summing up, the results of the field test support the three hypotheses. Over the period of 8 weeks the group with the artifact had a better room climate in respect to $\mathrm{CO}_{2}$. The results of the questionnaire also support the effectiveness of the artifact in respect to subjective artifact perception.

\section{Conclusion}

In this paper we suggested a novel design for a monitoring system to help the user comprehend and further improve indoor air quality, in order to prevent negative effects correlated with poor indoor air quality. Although prior research in domains such as "informative art systems" [52] or "ambient information systems" [53] also present innovative systems, the depicted designs focus on showing what is technically possible rather than finding reliable empirical evidence for their effectiveness. Commercially available systems reveal severe limitations, especially in respect to sustainable user engagement. By incorporating art, the proposed design of our artifact connects with the user on an emotional level, helps understanding the monitored values and integrates perfectly into the surroundings. The evaluation of the artifact was done by a demonstration in a field experiment. The field experiment provides evidence for the positive impact of the artifact. More specifically, the study contributes to research on IS-enabled visual feedback systems. In the course of our study we highlighted the importance of small details on feedback design and implementation that may have substantial effects on behavior.

Following the DSR Methodology, the findings of this research approve the design for this specific use-case of an IAQ IS and provide motivations for future adaptions to the artifact. In the context of the school, we are going to extend the field test over the course of a whole school year. This allows us to evaluate the long-term system engagement and further evaluate the impact on student performance and health, as measured in yearly grades and in sick students over the course of a year. However, future experimental setups will be dedicated to a more fundamental research questions, i.e. "Are hedonic, art-based IS superior to utilitarian, non-art-based IS in respect 
to usage and impact?" Ultimately, we intend to derive a design theory for art-based IS.

While the focus of this paper is on room-climate and ventilation, other data can be monitored in real-time. Data produced by the increasing number of connected sensors in everyday life could also modify similar art devices. Apart from the school context, we are currently also investigating the applicability of our solution to the case of diabetes through visualizing glucose levels as well as HbA1c. By providing a similar feedback system, we hope to help patients manage their diabetes mellitus more effective.

\section{References}

1. Skov, P., Valbjorn, O., Pedersen, B. V: Influence of Indoor Climate on the Sick Building Syndrome in an Office Environment. The Danish Indoor Climate Study Group. Scand. J. Work. Environ. Health. 16, 363-371 (1990).

2. Chaudhry, B.: Systematic Review: Impact of Health Information Technology on Quality, Efficiency, and Costs of Medical Care. Ann. Intern. Med. 144, 742 (2006).

3. Shekelle, P.G., Morton, S.C.S., Keeler, E.E.B.: Costs and benefits of health information technology. Evid. Rep. Technol. Assess. (Full. Rep). 132, 1-71 (2006).

4. Goldzweig, C., Towfigh, A., Maglione, M., Shekelle, P.: Costs and benefits of health information technology: new trends from the literature. Health Aff. 28, 282-293 (2009).

5. Brug, J., Glanz, K., Van Assema, P., Kok, G., van Breukelen, G.J.P.: The Impact of Computer-Tailored Feedback and Iterative Feedback on Fat, Fruit, and Vegetable Intake. Heal. Educ. Behav. 25, 517-531 (1998).

6. Strecher, V., Kreuter, M., Den Boer, D., Kobrin, S., Hospers, H.J., Skinner, C.S.: The effects of computer-tailored smoking cessation messages in family practice settings. J. Fam. Pract. 39, 262-268 (1994).

7. Baker, A., Wardle, J.: Increasing Fruit and Vegetable Intake Among Adults Attending Colorectal Cancer Screening The Efficacy of a Brief Tailored Intervention. Cancer Epidemiol. Biomarkers Prev. 11, 203-206 (2002).

8. Kreuter, M.W., Strecher, V.J.: Do tailored behavior change messages enhance the effectiveness of health risk appraisal? Results from a randomized trial. Health Educ. Res. 11, 97-105 (1996).

9. Noar, S.M., Benac, C.N., Harris, M.S.: Does tailoring matter? Meta-analytic review of tailored print health behavior change interventions. Psychol. Bull. 133, 673-93 (2007).

10. Abrams, D.B., Orleans, C.T., Niaura, R.S., Goldstein, M.G., Prochaska, J.O., Velicer, W.: Integrating individual and public health perspectives for treatment of tobacco dependence under managed health care: a combined stepped-care and matching model. Ann. Behav. Med. 18, 290-304 (1996).

11. Webb, T.L., Joseph, J., Yardley, L., Michie, S.: Using the internet to promote health behavior change: a systematic review and meta-analysis of the impact of theoretical basis, use of behavior change techniques, and mode of delivery on efficacy. J. Med. Internet Res. 12, e4 (2010).

12. Glasgow, R.E., Bull, S.S., Piette, J.D., Steiner, J.F.: Interactive behavior change technology. A partial solution to the competing demands of primary care. Am. J. Prev. Med. 27, 80-7 (2004). 
13. Richardson, C.R., Brown, B.B., Foley, S., Dial, K.S., Lowery, J.C.: Feasibility of adding enhanced pedometer feedback to nutritional counseling for weight loss. J. Med. Internet Res. 7, e56 (2005).

14. Wing, R.R., Tate, D.F., Gorin, A. a, Raynor, H. a, Fava, J.L.: A self-regulation program for maintenance of weight loss. N. Engl. J. Med. 355, 1563-1571 (2006).

15. Tate, D.F., Jackvony, E.H., Wing, R.R.: Effects of Internet behavioral counseling on weight loss in adults at risk for type 2 diabetes: a randomized trial. JAMA. 289, 1833-1836 (2003).

16. Fjeldsoe, B.S., Marshall, A.L., Miller, Y.D.: Behavior change interventions delivered by mobile telephone short-message service. Am. J. Prev. Med. 36, 165-73 (2009).

17. Nestoriuc, Y., Martin, A.: Efficacy of biofeedback for migraine: a meta-analysis. Pain. 128, $111-27$ (2007).

18. Nakao, M., Yano, E., Nomura, S., Kuboki, T.: Blood Pressure-Lowering Effects of Biofeedback Treatment in Hypertension: A Meta-Analysis of Randomized Controlled Trials. Hypertens. Res. 26, 37-46 (2003).

19. Carver, C.S., Scheier, M.F.: Control theory: A useful conceptual framework for personality-social, clinical, and health psychology. Psychol. Bull. 92, 111-135 (1982).

20. Wiener, N.: Cybernetics: Control and communication in the animal and the machine. Methuen, Cambridge, MA (1948).

21. Dignum, F., Kinny, D., Sonenberg, L.: From desires, obligations and norms to goals. Cogn. Sci. Q. 2, 405-427 (2002).

22. Kenkel, D.: Health behavior, health knowledge, and schooling. J. Polit. Econ. 99, 287-305 (1991).

23. Myerson, J., Green, L.: Discounting of delayed rewards: Models of individual choice. J. Exp. Anal. Behav. 3, 263-276 (1995).

24. Gershon, N., Eick, S.G., Card, S.: Information visualization. interactions. 5, 9-15 (1998).

25. Davis, F.: Perceived Usefulness, Perceived Ease of Use, and User Acceptance of Information Technology. MIS Q. 13, 319-340 (1989).

26. Gershon, N., Page, W.: What storytelling can do for information visualization. Commun. ACM. 44, 31-37 (2001).

27. American Psychiatric Association: Diagnostic and Statistical Manual of Mental Disorders. DSM-IV-TR. American Psychiatric Association, Washington, DC (2000).

28. Nakajima, T., Lehdonvirta, V., Tokunaga, E., Kimura, H.: Reflecting human behavior to motivate desirable lifestyle. Proceedings of the 7th ACM conference on Designing interactive systems - DIS '08. pp. 405-414. ACM Press, New York, New York, USA (2008).

29. Nakajima, T., Lehdonvirta, V.: Designing Motivation Using Persuasive Ambient Mirrors. Pers. Ubiquitous Comput. 17, 107-126 (2011).

30. Brown, J.S., Denning, S., Groh, K., Prusak, L.: Storytelling in Organizations. Why Storytelling is Transforming 21st Century Organizations and Management. Elsevier, Burlington, MA (2005).

31. Lamme, V. a. F.: Why visual attention and awareness are different. Trends Cogn. Sci. 7, 12-18 (2003).

32. Carver, C.S.: Facilitation of physical aggression through objective self-awareness. J. Exp. Soc. Psychol. 10, 365-370 (1974).

33. Carver, C.S.: Physical aggression as a function of objective self-awareness and attitudes toward punishment. J. Exp. Soc. Psychol. 11, 510-519 (1975).

34. Fenigstein, A., Scheier, M.F., Buss, A.H.: Public and private self-consciousness: Assessment and theory. J. Consult. Clin. Psychol. 43, 522-527 (1975). 
35. Greenberg, J.: Attentional focus and locus of performance causality as determinants of equity behavior. J. Pers. Soc. Psychol. 38, 579-585 (1980).

36. Hevner, A., March, S., Park, J., Ram, S.: DESIGN SCIENCE IN INFORMATION SYSTEM RESEARCH. MIS Q. 28, 75-105 (2004).

37. Peffers, K., Tuunanen, T., Rothenberger, M. a., Chatterjee, S.: A Design Science Research Methodology for Information Systems Research. J. Manag. Inf. Syst. 24, $45-77$ (2007).

38. Rigger, P., Wortmann, F.: An Art-Based IS for Improving Room-Climate. Advancing the Impact of Design Science: Moving from Theory to Practice. pp. 413-417. Springer (2014).

39. Climatemeter Temperature/Humidity

Lufft, http://www.lufft.com/en/products/temperaturehumidity/climatemeter-511099/.

40. The Netatmo Wheater Station, http://www.netatmo.com/en-US/product.

41. Hallnäs, L., Redström, J.: Slow Technology - Designing for Reflection. Pers. Ubiquitous Comput. 5, 201-212 (2001).

42. Kulkarni, A.: Design Principles of a Reactive Behavioral System for the Intelligent Room. Bitstream MIT J. EECS Student Res. 1-6 (2002).

43. Ferscha, A.: A Matter of Taste. Ambient Intell. 287-304 (2007).

44. Raspberry Pi | An ARM GNU/Linux box, http://www.raspberrypi.org.

45. CO2Meter.com CO2, Temperature, Humidty, Environmental Data Logger, http://www.co2meter.com/collections/co2-sensors/products/k33-environmental-logger-co2sensor.

46. PostgresSQL, http://www.postgresql.org.

47. node.js, http://nodejs.org.

48. Scheff, P.A., Paulius, V.K., Huang, S.W., Conroy, L.M.: Indoor air quality in a middle school, Part I: Use of $\mathrm{CO} 2$ as a tracer for effective ventilation. Appl. Occup. Environ. Hyg. 15, 824-34 (2000).

49. Scheff, P.A., Paulius, V.K., Curtis, L., Conroy, L.M.: Indoor air quality in a middle school, Part II: Development of emission factors for particulate matter and bioaerosols. Appl. Occup. Environ. Hyg. 15, 835-42 (2000).

50. Ferng, S.-F., Lee, L.-W.: Indoor air quality assessment of daycare facilities with carbon dioxide, temperature, and humidity as indicators. J. Environ. Health. 65, 14-18, 22 (2002).

51. Bandura, A.: Self-efficacy: Toward a unifying theory of behavioral change.

52. Holmquist, L., Skog, T.: Informative art: information visualization in everyday environments. Proc. 1st Int. Conf. Comput. Graph. Interact. Tech. Australas. South East Asia. (2003).

53. Pousman, Z., Stasko, J.: A Taxonomy of Ambient Information Systems. Proceedings of the working conference on advanced visual interfaces - AVI '06. p. 67. ACM Press, New York, New York, USA (2006). 